\title{
Different genetic backgrounds for malnutrition-related diabetes and Type 1 (insulin-dependent) diabetes mellitus in South Indians
}

\author{
C.B.Sanjeevi ${ }^{1}$, V.Seshiah ${ }^{2}$, E.Möller ${ }^{1}$ and O. Olerup ${ }^{1}$ \\ 1. Center for BioTechnology, Karolinska Institute, NOVUM, and Department of Clinical Immunology, Karolinska Institute at Huddinge \\ Hospital, Huddinge, Sweden, ${ }^{2}$ Department of Diabetology, Madras Medical College and Government General Hospital, Park Town, \\ Madras, India
}

\begin{abstract}
Summary. HLA-DRB, -DQA and -DQB genes were studied in ten South Indian malnutrition-related diabetic patients, ten Type 1 (insulin-dependent) diabetic patients and 45 control subjects, by TaqI restriction fragment length polymorphism analysis. The DR7,DQw9 haplotype was found to be frequent in patients with malnutrition-related diabetes $(p<0.01)$. The DRw17,DQw2 haplotype was overrepresented in the patients with Type 1 diabetes compared to control subjects $(p<0.05)$. In vitro amplification of the polymorphic second exon of DQB genes by the polymerase chain reaction technique was performed on DNA from 10 malnutrition-related diabetic patients, 10 Type 1 diabetic patients and 13 control subjects, as they belong to a new population. Hybridization with sequence-specific oligonucleotide probes for DQB1 alleles showed homozygosity of aspartic acid at
\end{abstract}

position 57 in 7 of 10 malnutrition-related diabetic patients compared to 2 of 10 Type 1 diabetic $(p<0.05)$ and 15 of 45 control subjects $(p<0.05)$. Homozygosity of non-aspartic acid at position 57 was present in 7 of 10 Type 1 diabetic compared to 0 of 10 malnutrition-related diabetic patients $(p<0.005)$ and 3 of 45 control subjects $(p<0.05)$. This study has confirmed the association of DQB1 57 non-asp in South Indians with Type 1 diabetes. In addition, our data clearly show that the genetic background of malnutrition-related diabetes mellitus is different from that of Type 1 diabetes.

Key words: Type 1 (insulin-dependent) diabetes mellitus, malnutrition-related diabetes mellitus, South Indians, HLADQ, genetic susceptibility.
Malnutrition-related diabetes mellitus (MRDM) has been recognised as a disease entity separate from Type 1 (insulin-dependent) diabetes mellitus and Type 2 (non-insulin-dependent) diabetes mellitus, by the World Health Organisation [1]. It has been referred to by various names, such as Tropical Diabetes [2], J-type diabetes [3], Z-type diabetes [4], Type 3 diabetes mellitus [5]. The patients are young, with a male predominance, underweight, require insulin for their glycaemic control, need high maintenance doses of insulin, but on withdrawal of insulin do not develop ketosis and may or may not have pancreatic calculi [6]. Thus, MRDM clinically resembles Type 1 diabetes except for the absence of ketosis. A study from Madras shows a $3.2 \%$ prevalence of MRDM as compared to $0.97 \%$ for Type 1 diabetes [5].

For research purposes, MRDM has been divided into fibrocalculous pancreatic diabetes and protein-deficient pancreatic diabetes [1]. Many clinical features of MRDM are common to both subtypes. There is no evidence as yet that these types are aetiologically different from Type 1 diabetes. Few genetic studies have been performed in this group. Analysis of HLA class I and II alleles in Ethiopians with MRDM has shown a positive association of MRDM with HLA-DR3 but not with DR4. As in Type 1 diabetes, the frequency of DR2 was decreased in patients with MRDM [7].

In this study, HLA class II genes (DRB, DQA, DQB) were studied in 10 South Indian MRDM patients and compared with 10 Type 1 diabetic patients and 45 healthy control subjects from the same ethnic background in order to elucidate whether MRDM is genetically associated with Type 1 diabetes, in a South Indian population.

\section{Subjects and methods}

\section{Subjects}

Ten patients with MRDM and 10 Type 1 diabetic patients were chosen for the study from patients of the Department of Diabetology, Madras Medical College and Government General Hospital, Madras. Forty-five healthy control subjects were studied. All the patients and control subjects studied were unrelated. Informed consent was obtained from the subjects for the study, which was carried out under the guidelines of the declaration of Helsinki. 
Table 1. Distribution (\%) of DR-DQ haplotypes associated with Type 1 (insulin-dependent) diabetes mellitus or malnutrition-related diabetes mellitus (MRDM) in various ethnic groups, seen in patients from South India

\begin{tabular}{llllcccc}
\hline DR-DQ haplotype & DQB1 & $\begin{array}{l}\text { DQB1 } \\
\text { codon 57 }\end{array}$ & $\begin{array}{l}\text { Type 1 } \\
\text { diabetes } \\
n=10\end{array}$ & $\begin{array}{l}\text { MRDM } \\
n=10\end{array}$ & $\begin{array}{l}\text { Control } \\
\text { subjects } \\
n=45\end{array}$ & $\begin{array}{l}\text { Type 1 diabetic } \\
\text { patients vs } \\
\text { control subjects }\end{array}$ & $\begin{array}{l}\text { MRDM } \\
\text { patients vs } \\
\text { control subjects }\end{array}$ \\
\hline DRw17,DQw2 & 0201 & NA & 60 & 10 & 9 & $p<0.05$ & NS \\
DR4,DQw8 & 0302 & NA & 30 & 0 & 24 & NS & NS \\
DR7,DQw9 & 0303 & A & 10 & 60 & 7 & NS & NS \\
DR9,DQw9 & 0303 & A & 0 & 0 & 0 & NS & NS \\
DRw15,DQw6 & 0601 & A & 10 & 40 & 51 & & \\
\hline
\end{tabular}

NA denotes DQ beta chain not carrying aspartic acid at position 57; A denotes DQ beta chain with aspartic acid at position 57

\section{Southern blot analysis}

DNA was isolated from peripheral blood leucocytes. Restriction enzyme digestion ( Taq I), agarose gel electrophoresis, capillary blotting to nylon membranes, hybridization, stringency washes and autoradiography were performed by standard techniques [8].

\section{TaqI DRB, DQA and DQB RFLP analysis}

DR andDQ typing wasperformed by hybridizing Taq I cleavedDNA with DRB, DQA and DQB probes. Allelic restriction fragment patterns were analysed as previously described $[9,10]$. The nomenclature used was adapted to the serologically defined DR and DQ specificities that are associated with the different allelelic Taq I DRBDQA-DQB haplotypes [9]. All MRDM and Type 1 diabetic patients and control subjects were DR and DQ typed by Taq I restriction fragment length polymorphism (RFLP) analysis. The distinction between DR7,DQw9 and DR9,DQw9 was made by digesting the genomic DNA with Msp I and hybridising with a DQA probe [11].

\section{DNA amplification and dot blot analysis}

The polymorphic second exon of the DQA and DQB genes was amplified in DNA from $10 \mathrm{MRDM}$ and 10 Type 1 diabetic patients, 13 control subjects (as they belong to a new population) and 26 homozygous cell lines representing 13 DQB alleles and 7 DQA alleles. The homozygous cell lines were used as amplification and hybridization controls. Amplification by polymerase chain reaction (PCR) was performed in a programmable thermal cycler (Perkin Elmer, Cetus, Conn, USA). DQB: 30 cycles of amplification; $95^{\circ} \mathrm{C} 1 \mathrm{~min}$ for denaturation, $55^{\circ} \mathrm{C}$ for $1 \mathrm{~min}$ for annealing and $72^{\circ} \mathrm{C}$ for $1 \mathrm{~min}$ for extension. DQA: 35 cycles of amplification; $94^{\circ} \mathrm{C}$ for 1 min for denaturation, $62^{\circ} \mathrm{C}$ for $1 \mathrm{~min}$ for annealing and $72^{\circ} \mathrm{C}$ for $2 \mathrm{~min}$ for extension [12]. The sequences of the primers used for the amplification of DQA and DQB second exons were obtained from Erlich and Bugawan [12]. The PCR amplified product was manually dot blotted onto nylon membranes. $3^{\prime}$ end-labelling of synthetic oligonucleotide probes with ${ }^{32} \mathrm{P}$, prehybridization, hybridization and stringency washes were performed as previously described [13]. The PCR amplified DQB genes were hybridised with the sequence-specific oligonucleotides (SSO) probes as previously described [14]. The SSO probes used for hybridising the DQA PCR products were made centering around the polymorphic DQA1 positions.

\section{Statistical analysis}

Comparisons of haplotype frequencies between the diabetic and the control groups were made by Fisher's exact test. Probability values were corrected for the number of comparisons made $(n=25)$ and considered significant if less than 0.05 .

\section{Results}

The informative haplotypes associated with Type 1 diabetes and MRDM are shown in Table 1. As in other ethnic groups, the DRw17,DQw2 haplotype was significantly associated with Type 1 diabetes in South Indians but the frequency of the DR4,DQw8 haplotype was not increased. In South Indian MRDM patients, the DR7,DQw9 haplotype was found to be significantly increased $(p<0.01)$. The DRw15,DQw6 haplotype was not significantly different in MRDM when compared to the control subjects.

The presence of aspartic acid (A) or neutral amino acids (NA) at position 57 of the DQ beta chain in the groups studied is shown in Figure 1. The susceptibility for Type 1 diabetes in South Indians was associated with NA homozygosity as in other Caucasian populations. Seven out of 10 Type 1 diabetic patients were NA homozygous as compared to 3 of 45 contol subjects $(p<0.05)$. A/NA heterozygosity was seen in only 1 of 10 Type 1 diabetic patients compared to 27 of 45 control subjects. None of The MRDM patients were DQ beta 57 NA homozygous. Homozygosity of $A$ was found in 7 of the 10 MRDM patients but in only 2 out of 10 in Type 1 diabetic patients $(p<0.05)$ and 15 of 45 control subjects $(p<0.05)$. NA homozygosity was significantly different between Type 1 diabetes and $\operatorname{MRDM}(p<0.005)$.

Analysis of DQA1 allelles by PCR amplification and using SSO probes helped in the identification of four major categories: A1 (alleles DQA1*0101, DQA1*0102 and DQA $1 * 0103$ ); A2 (allele DQA $1 * 0201$ ); A3 (DQA $1 * 0301)$ and A4 (DQA $1 * 0401$, DQA $1 * 0501$ and DQA $1 * 0601$ ) [15]. There was no significant difference between any of the groups.

\section{Discussion}

This study demonstrates that the DRw17,DQw2 haplotype was found more in South Indian Type 1 diabetic patients than in control subjects. This finding is in agreement with a study done on North Indians of Punjabi origin [16, $17]$ and in South Indians $[18,19]$ and the DR and DQ association seen in Asian Indians has been identified as being similar to those of Caucasians $[16,18]$. Studies on Caucasians show that individuals possessing DR3 or DR4 are 


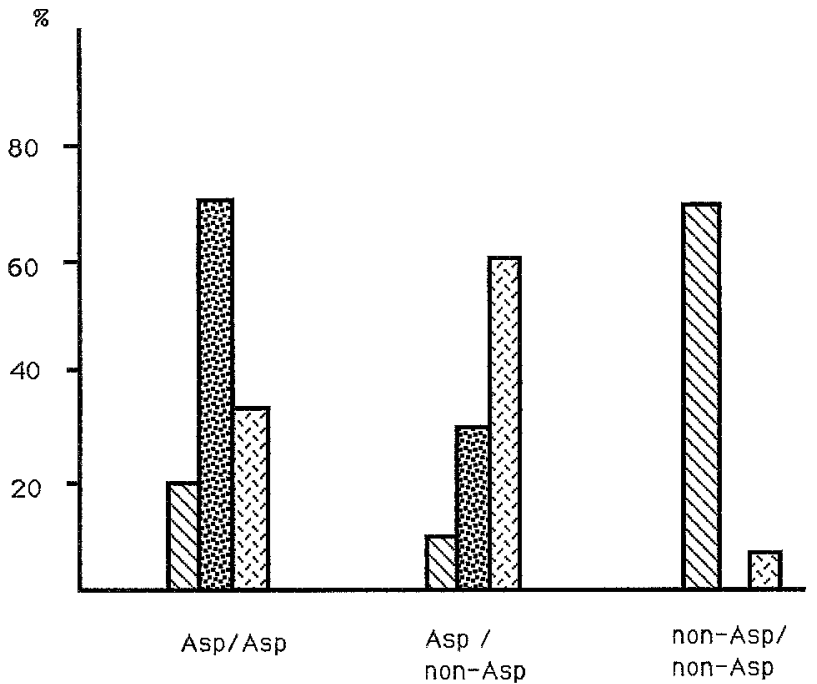

Fig. 1. Frequencies (\%) of Asp and non-Asp at position 57 of the HLA-DQ beta chain in patients with Type 1 (insulin-dependent) diabetes mellitus $\mathrm{N}$ or malnutrition-related diabetes mellitus (MRDM) G compared to control subjects B. All patients and control subjects were HLA-DR and -DQ typed by Taq I restriction fragment length polymorphism (RFLP) analysis. The DQB results obtained by amplification using polymerase chain reaction and sequence specific oliginucleotide probing (PCR-SSO) in MRDM patients, Type 1 diabetic patients, 13 control subjects and 26 cell lines were found identical to the Taq I RFLP. The amino acid at position 57 of the DQ beta chain was inferred in the remaining control subjects

more prone to develop Type 1 diabetes, and a combination of both DR3 and DR4 in an individual also increases the likelihood of developing the disease [20]. OtherDRantigens which show positive association with Type 1 diabetes are DR1 and DRw8 [21]. The DR association with Type 1 diabetes varies with ethnic group. Association with DR7 is found in the Negroid race [22]; DR4 and DR9 in the Japanese [23]; DR3 and DR9 in the Chinese [24]. Conversely, the DRw15,DQw6,Dw2 haplotype is negatively associated with Type 1 diabetes in all the ethnic groups studied.

Clinically and biochemically the important features which distinguish MRDM from Type 1 diabetes, are the absence of diabetic ketoacidosis on withdrawal of insulin, requirement of high doses of insulin [25] to maintain euglycaemic state (more than $2 \mathrm{IU} / \mathrm{kg}$ body weight) and presence of significantly higher C-peptide levels [26]. In this study, the MRDM patients from South India were frequently positive for the DR7,DQw9 haplotype. This haplotype is not associated with Type 1 diabetes in Caucasians and is seen only in $10 \%$ of the South Indians with Type 1 diabetes and $7 \%$ of the control subjects. Based on this finding, MRDM in South Indians could be identified as a disease immunogenetically distinct from Type 1 diabetes in South Indians.

MRDM was shown to be associated with DR3 in a study from Ethiopia. It was postulated that the genetic basis for susceptibility to MRDM and Type 1 diabetes could be partially identical in that ethnic group [7]. This finding of a DR3 association with MRDM in Ethiopians could not be confirmed in South Indians.
Studies on Type 1 diabetes in Ethiopians, Caucasians and South Indians show that DR3 and/or DR4 to be disease-associated antigens in all three populations. Clinically and biochemically MRDM in Ethiopians is similar to MRDM in South Indians [26, 27]. However, the HLA studies on MRDM do not show a similarity in these two populations. Earlier immunological studies on MRDM are very few and show conflicting results. According to Ahuja [25], islet cell antibodies are absent in MRDM patients but this finding has been disputed by Hazra and coworkers [28]. Narentranathan has shown a familial tendency in tropical pancreatic syndrome with diabetes [29].

Analysis of the HLA-DQ genes has shown that the codon for aspartic acid (Asp) in position 57 is protective to the development of Type 1 diabetes in Caucasians [30]. When Japanese Type 1 diabetic subjects were investigated for the presence or absence of Asp 57 in the DQ beta chain, it was shown that all their patients studied had Asp at position 57, indicating that it does not confer protection to Type 1 diabetes in the Japanese [31]. A similar finding was obtained in the Chinese [32]. As the majority of the Type 1 diabetic patients studied in this report were non-Asp (NA) homozygous compared to the control subjects, it looks like homozygosity of NA is an important susceptibility factor for the development of Type 1 diabetes in South Indians. Alleles of the DQA1 locus have also been implicated in the susceptibility to Type 1 diabetes along with the DQB1 locus in Caucasians, Negroid [33] and the Japanese [34].

There was a significant increase of the Asp-bearing DR7,DQw9 haplotype in MRDM patients when compared to the control subjects. None of the MRDM patients studied were NA homozygous.

Our findings show that the DR3 association with Type 1 diabetes in South Indians is similar to the HLADR3 association described in Caucasian patients. It is likely therefore that the immunogenetic basis for the disease is identical between the two populations. One can argue that South Indians are similar to Caucasians since the frequencies of polymorphic HLA class I and class II antigens do not differ significantly between these populations. However, one exception is the low frequency of the protective haplotype, DRw15,DQw6,Dw2 in South Indians (Sanjeevi CB et al., unpublished data), when compared to Caucasians. DRw15,DQw6,Dw12 is the commonly observed DRw15 haplotype in South Indians. MRDM, on the other hand, is a frequent disease in South Indians but rare in Caucasians. One earlier study has indicated that MRDM is an HLA-associated disease and that the immunogenetic background is identical between Type 1 diabetes and MRDM in Ethiopians. Our results are different; we did not find a high frequency of DR3 (DRw17) or DR4 positive haplotypes in our MRDM patients. Therefore, we conclude that the genetic background of MRDM differs from Type 1 diabetes. The high familial occurrence of MRDM indicates a genetic component, but it is still too early to conclude that MRDM is an HLA-associated disease. It has not been confirmed whether MRDM is an autoimmune disorder. Further studies should concentrate on trying to establish the genetic linkage of MRDM with the specific aim of identi- 
fication as an HLA-linked disease. Studies of families with both MRDM and Type 1 diabetes need to be done. Thereafter, larger patient groups will be needed to establish and identify the possible HLA association of MRDM.

Acknowledgements. The study was supported by a grant from the Swedish Medical Research Council (Grant No.00793). C. B. Sanjeevi was supported by a visiting scientist fellowship from the Karolinska Institute.

\section{References}

1. WHO study group on Diabetes (1985) WHO technical Report series 727

2. Abu-Bakare A, Taylor R, Gill GV, Alberti KGMM (1986) Tropical or malnutrition-related diabetes: a real syndrome? Lancet I: $1135-1138$

3. Hugh-Jones P (1955) Diabetes in Jamaica. Lancet II: 891-897

4. Zuidema PJ (1959) Cirrhosis and disseminated calcification of the pancreas with malnutrition. Trop Geogr Med 11:70-74

5. Seshiah V, Sundaram A, Hariharan RS, Ramanakumar TK, Ganesan VS, Moses SGP (1984) Insulin requiring diabetes mellitus (IRDM): Type III Diabetes mellitus. Diabetol Croat 13: 311-315

6. Sanjeevi CB, Seshiah V, Venkataraman S, Hariharan RS (1988) Fibrocalculous pancreatic diabetes (Radiodiagnosis). J Appl Med 14: 727-728

7. Abdulkadir J, Worku Y, Schreuder GMT, D'Amaro J, DeVries RRP, Ottenhoff THM (1989) HLA.DR antigens in malnutrition-related diabetes mellitus in Ethiopians: a clue to its etiology? Tissue Antigens 34: 284-289

8. Olerup O, Hillert J, Fredrikson S et al. (1989) Primarily chronic progressive and relapsing/remitting multiple sclerosis: Two immunogenetically distinct disease entities. Proc Natl Acad Sci USA 86: 7113-7117

9. Carlsson B, Wallin J, Böhme J, Möller E (1987) HLA-DR-DQ haplotypes defined by restriction fragment length analysis: correlation to serology. Human Immunol 20:95-113

10. Bidwell JL, Bidwell EA, Savage DA, Middleton D, Klauda PT, Bradley BA (1988) A DNA-RFLP typing system which positively identifies serologically well-defined and ill-defined HLA-DR and -DQ alleles, including DRw10. Transplantation 45: 640-646

11. Bidwell JL, Bignon JD (1991) DNA RFLP methods and interpretation scheme for HLA-DR and DQ typing. Eur J Immunogen 18: 5-22

12. Erlich HA, Bugawan BL (1989) HLA class II gene polymorphism: DNA typing, evolution, and relationship to disease susceptibility. In: Erlich HA (ed) PCR Technology-Principles and applications for DNA amplification. M Stockton press, New York, pp 193-208

13. Rønnigen KS, Iwe T, Halstensen TS, Spurkland A, Thorsby E (1989) The aminoacid at position 57 of the HLA-DQ beta chain and susceptibility to develop insulin-dependent diabetes mellitus. Hum Immunol 26: 215-225

14. Lundin KEA, Rønningen KS, Aono S et al. (1989) HLA-DQ antigens and DQB amino acid 57 of Japanese patients with insulin dependent diabetes mellitus: detection of DRw8,DQw8 haplotype. Tissue Antigens 34: 233-241

15. Bodmer JG, Marsh SGE, Albert ED et al. (1991) Nomenclature for factors of the HLA system, 1990. Tissue Antigens 37: 97-104

16. Fletcher J, Odugbesan O, Mijovic C, Mackay E, Bradwell AR, Barnett AH (1988) Class II HLA DNA polymorphisms in Type 1 (insulin-dependent) diabetic patients of North Indian origin. Diabetologia $31: 343-350$

17. Jenkins D, Mijovic C, Fletcher J, Jacobs KH, Bradwell AR, Barnett AH (1990) Identification of suceptibility loci for Type 1 (in- sulin-dependent) diabetes by trans-racial gene mapping. Diabetologia 33: 387-395

18. Serjeantson SW, Ranford PR, Kirk RL et al. (1987) HLA-DR and $-D Q D N A$ genotyping in insulin-dependent diabetes patients in South India. Disease Markers 5: $101-108$

19. Easteal S, Viswanathan M, Serjeantson SW (1990) HLA-DP, DQ and -DR RFLP types in South Indian insulin-dependent diabetes mellitus patients. Tissue Antigens $35: 71-74$

20. Thompson M, Molvig J, Zerbib A et al. (1987) HLA haplotype analysis in Danish HLA-DR3,4-positive insulin-dependent diabetics and controls. In: Dupont B (ed) Immunobiology of HLA, Springer, Berlin Heidelberg New York, pp 413-414

21. Nepom GT (1990) A unified hypothesis for the complex genetics of HLA associations with IDDM. Diabetes 39: 1153-1157

22. Fletcher J, Mijovic C, Odugbesan O, Jenkins D, Bradwell AR, Barnett AH (1988) Transracial studies implicate HLA-DQ as a component of genetic susceptibility to Type 1 (insulin-dependent) diabetes. Diabetologia 31:864-870

23. Bertrams J, Baur MP (1984) Insulin dependent diabetes mellitus. In: Albert ED, Baur MP, Mayr WR (eds) Histocompatibility testing, Springer, Berlin Heidelberg New York, pp 348-358

24. Bashir H, Juji T, Moffit P (1983) Diabetes mellitus. In: Simons MJ, Tait BD (eds) Proceedings of the Second Asia and Oceania Histocompatibility Workshop conference. Immunopublishing, Toorak, pp 332-342

25. Ahuja MMS (1985) Heterogeneity in tropical pancreatic diabetes. Diabetologia 28: 708 (Letter)

26. Mohan V, Mohan R, Susheela L et al. (1985) Tropical pancreatic diabetes in South India: heterogeneity in clinical and biochemical profile. Diabetologia 28: 229-232

27. Abdulkadir J, Mengesha B, Gebriel ZW, Gebre P, Bestall G, Thompson JA (1987) Insulin-dependent ketosis-resistant diabetes in Ethiopia. Trans Royal Soc Trop Med Hyg 81:539-543

28. Hazra DK, Singh R, Singh B, Gupta MK, Agarwal P, Mittal S (1984) Autoantibodies in a tropical ketosis resistant but insulin dependent diabetes mellitus. In: Bajaj JS (ed) Diabetes mellitus in developing countries. Interprint, New Delhi, pp 165-167

29. Narendranathan M (1981) Chronic calcific pancreatitis of the tropics. Trop Gastroenterol $2: 40-45$

30. Todd JA Bell JI, McDevitt HO (1987) HLA DQ beta gene contributes to susceptibility and resistance to insulin dependent diabetes mellitus. Nature 329:599-604

31. Yamagata K, Nakajima H, Hanafusa T et al. (1989) Aspartic acid at position 57 of DQ $\beta$ chain does not protect against Type 1 (insulin-dependent) diabetes mellitus in Japanese subjects. Diabetologia 32: $762-764$

32. Bao M, Wang J, Dorman JS, Trucco M (1989) HLA-DQ $\beta$ nonAsp-57 allele and incidence of Diabetes in China and the USA. Lancet II: $497-498$

33. Todd JA, Mijovic C, Fletcher J, Jenkins D, Bradwell AR, Barnett AH (1989) Identification of susceptibility loci for insulin-dependent diabetes mellitus by trans-racial gene mapping. Nature 338: $587-589$

34. Todd JA, Fukui Y, Kitagawa T, Sasazuki T (1990) The A3 allele of the HLA-DQA1 locus is associated with susceptibility to type I diabetes in Japanese. Proc Natl Acad Sci USA 87: 1094 1098

Received: 8 August 1991

and in revised form: 20 November 1991

Dr. C.B.Sanjeevi

Department of Molecular Diabetes Research

Wallenberg Laboratory II

Box 7031

S-22007 Lund

Sweden 